\title{
Review Article \\ Food-Derived Natural Compounds for Pain Relief in Neuropathic Pain
}

\author{
Eun Yeong Lim $^{1,2}$ and Yun Tai Kim ${ }^{1,2}$ \\ ${ }^{1}$ Research Group of Innovative Special Food, Korea Food Research Institute, No. 62, Anyangpangyo-ro, Bundang-gu, \\ Seongnam 13539, Republic of Korea \\ ${ }^{2}$ Department of Food Biotechnology, Korea University of Science and Technology, 217 Gajeong-ro, Yuseong-gu, \\ Daejeon 34113, Republic of Korea \\ Correspondence should be addressed to Yun Tai Kim; ytkim@kfri.re.kr
}

Received 5 August 2016; Revised 29 September 2016; Accepted 16 October 2016

Academic Editor: Blanca Hernandez-Ledesma

Copyright ( $) 2016$ E. Y. Lim and Y. T. Kim. This is an open access article distributed under the Creative Commons Attribution License, which permits unrestricted use, distribution, and reproduction in any medium, provided the original work is properly cited.

\begin{abstract}
Neuropathic pain, defined as pain caused by a lesion or disease of the somatosensory nervous system, is characterized by dysesthesia, hyperalgesia, and allodynia. The number of patients with this type of pain has increased rapidly in recent years. Yet, available neuropathic pain medicines have undesired side effects, such as tolerance and physical dependence, and do not fully alleviate the pain. The mechanisms of neuropathic pain are still not fully understood. Injury causes inflammation and immune responses and changed expression and activity of receptors and ion channels in peripheral nerve terminals. Additionally, neuroinflammation is a known factor in the development and maintenance of neuropathic pain. During neuropathic pain development, the $\mathrm{C}$ - $\mathrm{C}$ motif chemokine receptor 2 (CCR2) acts as an important signaling mediator. Traditional plant treatments have been used throughout the world for treating diseases. We and others have identified food-derived compounds that alleviate neuropathic pain. Here, we review the natural compounds for neuropathic pain relief, their mechanisms of action, and the potential benefits of natural compounds with antagonistic effects on GPCRs, especially those containing CCR2, for neuropathic pain treatment.
\end{abstract}

\section{Introduction}

The International Association for the Study of Pain (IASP) defines neuropathic pain as pain caused by a lesion or disease of the somatosensory nervous system, which causes unpleasant and abnormal sensation (dysesthesia), an increased response to painful stimuli (hyperalgesia), and pain in response to a stimulus that does not normally provoke pain (allodynia) [1, 2]. This definition of neuropathic pain distinguishes it from other types of pain, including musculoskeletal pain, by restricting its extent to the somatosensory nervous system.

According to previous studies, neuropathic pain affects about 1 in every 10 adults and the economic burden for treating this pain is increasing $[3,4]$. Langley and colleagues have described the importance of pain in terms of social impact and have shown that people experiencing neuropathic pain have an economic burden twice that of patients with chronic nonneuropathic pain, in five countries in Western Europe $[5,6]$.

There are four main types of pharmacological therapies for neuropathic pain: antidepressants, anticonvulsants, opioids, and topical agents. The first-line treatments for neuropathic pain, based on efficacy and safety, include antidepressants (e.g., tricyclic antidepressants [TCAs], serotoninnorepinephrine reuptake inhibitors [SNRIs]) and certain anticonvulsants (e.g., gabapentin, pregabalin, and topical lidocaine) [7]. Opioid analgesics have been recommended as second-line treatments, given their safety; however, they are sometimes used as first choice. Third-line treatments include certain antidepressant medications (e.g., bupropion, citalopram, and paroxetine) and certain anticonvulsants medications (e.g., carbamazepine, lamotrigine, oxcarbazepine, and N-methyl-D-aspartate [NMDA] receptor antagonists). However, these drugs are not completely effective in attenuating neuropathic pain, because of the complexity of this 
type of pain, and also have side effects, such as sedation, dizziness, edema, and ataxia $[8,9]$. For these reasons, there is interest in new agents for relieving neuropathic pain. Although the existing neuropathic pain animal model does not fully represent the human condition, it facilitates studies on nerve injury-induced pain and indicates neuropathic pain mediators. Natural products have been widely used for centuries to treat various diseases and can effectively treat diseases, without causing side effects [10], and may present therapeutic candidates for the development of new drugs to alleviate neuropathic pain.

The causes of neural damage can be diverse; these include diabetic neuropathy, human immunodeficiency virus (HIV) neuropathy, postherpetic neuralgia, drug-induced neuropathy, and traumatic nerve injury. Various neuropathic pain models have been developed, with consideration of different neuroimmune signaling pathways [11]. Tissue and nerve injury-induced hyperexcitability are due to immune cells and the inflammatory mediators that they release. In particular, it is well-known that neuroinflammation, which is a local inflammatory reaction in the nervous system, can lead to the development of neuropathic pain. In addition, ion channels open and close in response to chemical or mechanical signals, and $\mathrm{G}$ protein-coupled receptors (GPCRs) also stimulate hyperexcitability. GPCRs regulate ligand-gated and voltagedependent ion channels and are activated in response to inflammatory mediators that are released by peripheral tissues and immune cells.

In this review, we summarize the processes involved in neuropathic pain development and natural compounds that are useful for neuropathic pain alleviation and further discuss the potential benefits of $\mathrm{C}-\mathrm{C}$ motif chemokine receptor 2 (CCR2) antagonists for treatment of neuropathic pain.

\section{Mechanism of Neuropathic Pain}

Generally, pain perception involves the following processes: transduction, transmission, modulation, and perception. In brief, nociceptors switch noxious stimulation to nociceptive signals, which are transported into the central nervous system (CNS) along nerve fibers from the site of injury. These nociceptive signals are modulated at synaptic sites and in the CNS by ascending and descending pathways, and we recognize pain [12]. In neuropathic pain, nerve injury alters expression of genes encoding cytokine and chemokine receptors; ion channel expression at the membranes and substances released by immune cells induce nociceptive signaling in the peripheral and central nervous system and ultimately cause the development of neuropathic pain (Figure 1) $[13,14]$. Moreover neuroinflammation, that is, immune reaction in the peripheral and CNS, including activation of mast cells and glial cells, may occur due to nerve injury. These changes induce peripheral sensitization, which involves enhanced excitability of the primary afferent nociceptors that convert peripheral stimuli into action potentials that are propagated in the CNS [15]. Thus, peripheral sensory nerve hyperexcitability and central nerve hyperexcitability, involving diverse pathways, are the major reasons for the initiation, development, and maintenance of neuropathic pain [16]. After peripheral nerve injury, microglia in a resting state in the spinal dorsal horn and dorsal root ganglia (DRG) are activated through a series of cellular and molecular changes that are mainly produced by monocyte chemoattractant protein 1/C-C motif chemokine ligand 2 (MCP1/CCL2). This activation is commonly observed among various models of neuropathic pain [17].

2.1. Neuroimmune Interactions Are Mediated by Inflammatory Cytokines and Chemokines. Growing evidence indicates that inflammatory and immune responses contribute to neuropathic pain [18]. After nerve injury, immunocompromised mice show alleviation of neuropathic pain as compared with normal mice, in the early stage [19]. In addition, neuroinflammation induced by nervous system injury accompanies a neuroimmune interaction that activates immune cells and leads to development of chronic pain, including neuropathic pain. For instance excessive neuroinflammation, as found in Guillain-Barré syndrome and multiple sclerosis, is associated with neuropathic pain. In this regard, targeting neuroinflammation is also a promising analgesic approach for neuropathic pain $[20,21]$.

One characteristic of neuropathic pain is infiltration of blood leukocytes by chemokines [22]. Accumulating evidence has indicated that glial cell activation and the resulting expression of proinflammatory immune mediators, such as tumor necrosis factor- $\alpha$ (TNF- $\alpha$ ), interleukin- $1 \beta$ (IL- $1 \beta$ ), and brain-derived neurotrophic factor (BDNF), play critical roles in neuropathic pain $[23,24]$. In early life, nerve injury triggers anti-inflammatory responses, such as expression of IL-4 and IL-10 rather than proinflammatory mediators, supporting the supposition that infants rarely experience neuropathic pain [25].

We will describe immune responses focused on immune cells (mast cells, microglia, neutrophils, macrophages, Schwann cells, and T cells) and some of their inflammatory mediators. In a normal state, mast cells have granules that contain a variety of bioactive chemicals. Nervous injury triggers neuroinflammation, which activates mast cells, and activated mast cells in turn release inflammatory factors, such as bradykinin, prostaglandins, histamine, and substance $P$ [26]. Partial sciatic nerve ligation (PSNL) induces mast cell activation and degranulation and neutrophil and macrophage infiltration, which is reversed by treatment with a mast cell stabilizer. This suggests that mast cells are powerful neuropathic pain mediators [27]. Microglia, which are glial cells that are located throughout the CNS, become activated in response to nerve injury and immunological stimuli, including proinflammatory signals released from immune cells, such as mast cells. This interaction between mast cells and microglia regulates peripheral pain signaling. Microglia activation causes pain states by releasing proinflammatory cytokines, chemokines, and proteases [28]. Astrocytes, the most abundant glial cell type in the CNS, also play a major role in pain facilitation and are fundamental contributors to the neuropathic pain involved in neuroinflammation. Therefore, a promising therapeutic target for managing 


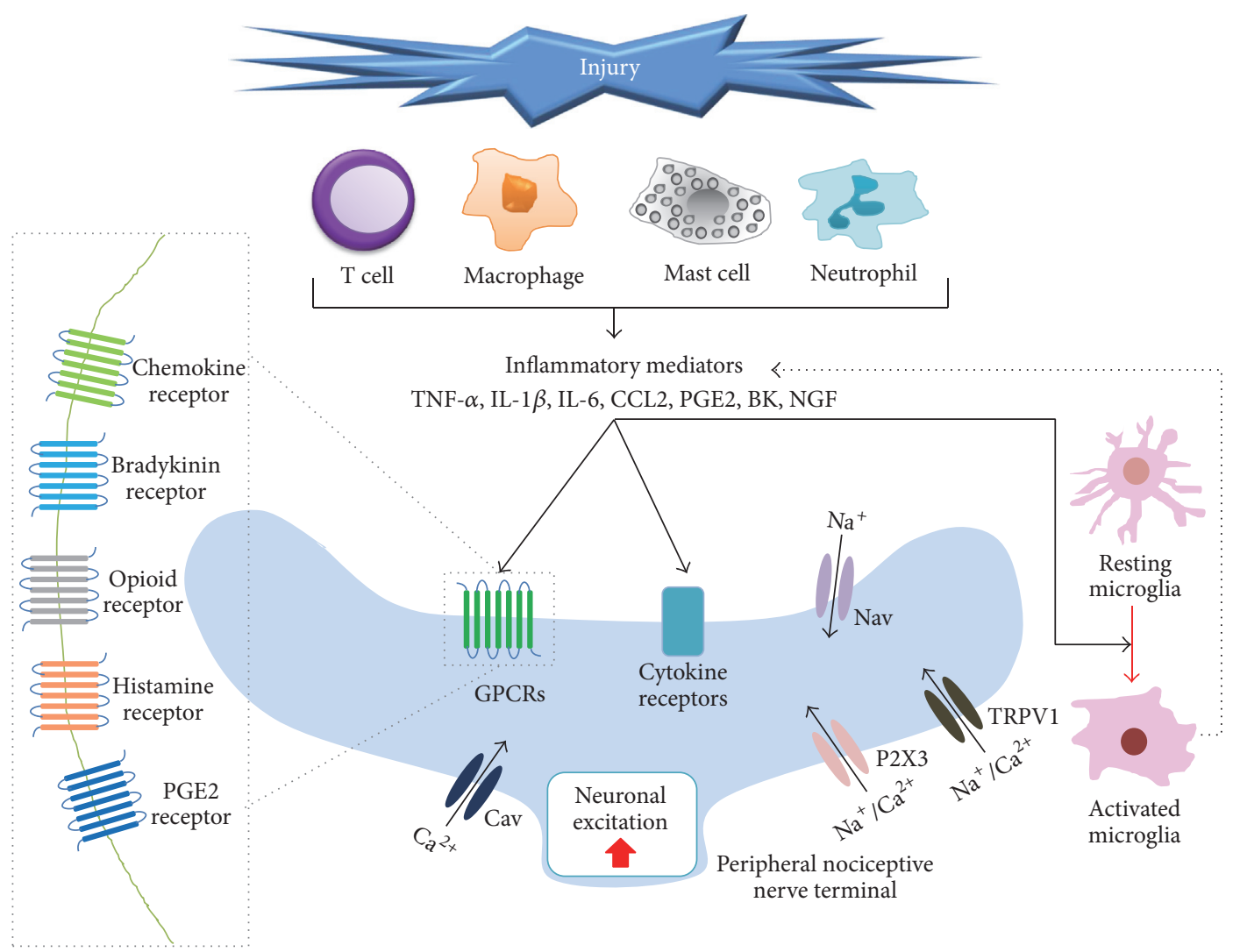

FIGURE 1: Mechanisms involved in peripheral sensitization in neuropathic pain. Tissue and nerve injury lead to inflammation, including neuroinflammation, via activation of immune cells ( $\mathrm{T}$ cells, macrophage, mast cell, and neutrophil), by releasing diverse inflammatory mediators, such as TNF- $\alpha$, IL-1 $\beta$, IL-6, CCL2, PGE2, BK, and NGF, in nearby peripheral nociceptive nerve terminal. These mediators act on their respective receptors, including TRPV1, P2X3, cytokine receptors, and G-coupled protein receptors. The activation of these receptors results in upregulation of $\mathrm{Ca}^{2+}$ and cyclic AMP, which related to several kinase signaling pathways. Altogether, these mechanisms can lead to neuronal excitation and microglial activation, as well as gene expression changes in sensory neurons. Overactivated microglia can also trigger neuropathic pain via inflammatory mediator-related signaling.

neuropathic pain would be factors that mediate mast and glia cell reactivity.

In a normal state, neutrophils, which are the first leukocytes to arrive at a site of tissue damage, accumulate in the epineurium after nerve injury, contributing to neuropathic pain [29]. Depletion of circulating neutrophils, by using antibodies, attenuates the induction of thermal hyperalgesia after PSNL but does not alleviate the typical hyperalgesia at day 8 after injury, suggesting that endoneurial accumulation of neutrophils is related to the development of neuropathic pain [30]. Macrophages are significantly increased in neuropathic pain models [11, 31]. Moreover, systemic depletion of macrophages reduces mechanical hypersensitivity, suggesting their importance in the generation of neuropathic pain [32]. Furthermore, the role of Schwann cells in the generation of neuropathic pain has been confirmed [33]. In a chronic constriction injury (CCI) rat model, Schwann cells release erythropoietin (EPO), while injection of EPO may protect against neuropathic pain $[34,35]$. CCI induces $\mathrm{T}$ cell infiltration, as well as mechanical allodynia and thermal hyperalgesia. These neuropathic pain symptoms are significantly reduced in rats lacking mature $\mathrm{T}$ cells, indicating that $\mathrm{T}$ cells are key immune cells in the development of neuropathic pain. There are two main T helper (Th) cell subtypes: Th1 cells and Th2 cells. Th1 cells produce proinflammatory cytokines and Th 2 cells produce anti-inflammatory cytokines. Injection of these two types has opposite effects: Thl cell injection enhances neuropathic pain symptoms, while Th2 injection reduces pain hypersensitivity [36].

A wide variety of experimental approaches have indicated that inflammatory mediators play crucial roles in neuropathic pain. Proinflammatory cytokines and chemokines have been associated with neuropathic pain and play critical roles in this condition by direct and indirect actions. Some of these factors can activate and sensitize nociceptors and thereby induce pain [37]. Furthermore, nerve injury produces proinflammatory cytokines: TNF- $\alpha$, IL- $1 \beta$, and IL6 and inflammatory mediators: prostaglandin, serotonin, bradykinin, and histamine, as well as neurotrophic factors, such as nerve growth factor (NGF). On the other hand, some immune cells can produce and release anti-inflammatory cytokines and opioid peptides, such as $\beta$-endorphin, which may induce analgesia and alleviate pain [38]. Taken together, these studies indicate that several immune cell types and their 
mediators are implicated in the development of neuropathic pain [18].

In a neuropathic pain model, IL- $1 \beta$ expression is upregulated in the injured sciatic nerve, DRG, and spinal cord [39-41]. Interestingly, the injection of an IL- $1 \beta$-neutralizing antibody was shown to alleviate the behavior related to neuropathic pain [40]. IL-1 $\beta$ functions to enhance excitatory synaptic transmissions and reduce inhibitory synaptic transmissions in the dorsal horn neurons [42]. It has also been reported that TNF- $\alpha$ was upregulated in a neuropathic pain model and this phenomenon was confirmed by specific inhibitor treatment $[43,44]$. $\mathrm{Xu}$ and colleagues have suggested that TNF- $\alpha$ may be a biomarker for chronic neuropathic pain in patients with spinal cord injury (SCI) [45]. Furthermore, IL- 6 is also a neuropathic pain-related proinflammatory cytokine. In a model involving partial ligation of the sciatic nerve, IL-6 expression was increased [46]. TNF$\alpha$ only enhances excitatory synaptic transmissions, while IL-6 reduces inhibitory synaptic transmission at the same spinal cord level [42]. Additionally, NGF-overexpressing mice showed hypersensitivity [47]. Moreover, MCP1, also known as CCL2, is a major inflammatory chemokine that is specifically responsible for recruiting monocytes into the site of inflammation. After nerve damage, MCP1 mRNA expression was significantly upregulated in the rat DRG [48]. In addition, intrathecal injection of MCP1 produces mechanical allodynia [48].

2.2. Regulation of Peripheral Nerve Excitability. Nerve injury increases expression of sodium channels in the DRG and around the terminal injury site of injured axons. Nav1.7 and Nav1.8 double-knockout mice normally develop neuropathic pain in PSNL animal model [49]. Nav1.7 is not required for oxaliplatin-induced neuropathic pain but is essential in CCI mice, suggesting that the neuropathic pain trigger affects the mechanism by which pain develops [50]. In addition, knockdown of Nav1.8 by means of siRNA alleviates mechanical allodynia in CCI rats [51].

Nav1.7 and Nav1.8 expression are also significantly increased in the lumber disc herniation model [52]. Nav1.3 is upregulated in the DRG after nerve injury, in line with the data showing that knockdown of Nav1.3 reduces pain in the neuropathic pain model $[53,54]$.

Drugs blocking sodium channels include lidocaine, mexiletine, phenytoin, carbazepine, oxcarbazepine, lamotrigine, and TCAs. These drugs, which are nonselective for channel subtypes, can alleviate neuropathic pain by interfering with spontaneous ectopic discharges but also have many side effects [55].

Voltage-gated calcium channels (Cav) also play a role in neuropathic pain development. T-type channel current density significantly increases after nerve injury, and inhibitors of this type of channel can reduce excitability in a neuropathic pain model $[56,57]$. Mice lacking the N-type channel show reduced responses to mechanical and thermal stimuli in neuropathic pain models [58].

Ligand-gated ion channels also have crucial roles in terms of the onset of neuropathic pain. Interestingly, agonists and antagonists of transient receptor potential vanilloid member 1 (TRPV1) are both effective in neuropathic pain alleviation. TRPV1 agonists release transmitters and induce cation influx into the nerve, as well as receptor desensitization [59]. Topical formulations of high-dose capsaicin have been shown to be efficacious in a number of neuropathic pain conditions, including Phase 3 studies in postherpetic neuralgia patients [60]. It has been reported that antagonists that block TRPV1 signal transduction can reverse heat-related hyperalgesia in sciatic nerve ligation in mice [61]. After chronic compression of the DRG, mechanical allodynia was enhanced by injection of a TRPV4 agonist but reversed by its antagonist [62]. Antagonists of NMDA receptors, which are subtypes of the glutamate receptor, are third-line treatments for neuropathic pain and can reduce pain in animal models but have many side effects, including sedation, confusion, and motor incoordination [63].

2.3. G Protein-Coupled Receptors (GPCRs). G protein-coupled receptors (GPCRs) comprise the largest superfamily of transmembrane receptors and transduce extracellular stimuli into intracellular responses. Targeting GPCRs is highly successful, so that $30 \%$ of drugs target GPCRs for conditions including allergies, hypertension, migraine, asthma, stroke, and pain [64]. GPCRs and their ligands play a number of important roles in the modulation of acute and chronic pain, including neuropathic pain [65].

2.3.1. GABA Receptors. Gamma-aminobutyric acid (GABA) is a widely distributed inhibitory neurotransmitter, also found in the spinal cord. It is well-known that hypofunction of GABAergic tone leads to development of neuropathic pain in animal models [66]. Treatment with GABA agonists reduces central neuropathic pain behavior and neuronal hyperexcitability after SCI. Injection of GABA after SCI attenuated mechanical allodynia and hyperexcitability of the spinal dorsal horn neurons. This reduction is regulated by both GABAA and GABAB receptors. Moreover, bicuculline, a GABAA receptor antagonist, induces hyperexcitability and pain behavior in normal rats [67]. The number of GABAergic interneurons is also decreased in a neuropathic pain model $[68,69]$.

2.3.2. Bradykinin Receptors. Bradykinin (BK), an inflammatory mediator, is a vasodilator and is known to induce neuropathic pain by binding to the $\mathrm{BK} 1$ and $\mathrm{BK} 2$ receptor. Several studies have shown the participation of kinins and their receptors in neuropathic pain development [90]. Nerve injury induces an increase in BK1 receptor $\mathrm{mRNA}$ in the spinal cord and sciatic nerve and also produces mechanical allodynia and hyperalgesia. The BK1-knockout mice show reduction in both allodynia and hyperalgesia in a neuropathic pain animal model. Inhibition of $\mathrm{BK} 1$ and $\mathrm{BK} 2$ reverses the effect of dynorphin $\mathrm{A}$, an endogenous opioid peptide, inducing persistent neuropathic pain [91].

2.3.3. Opioid Receptors. Most opioids are used as second- or third-line analgesics that may provide reasonable analgesia 
to some neuropathic pain [92]. Because opioid treatment may require relatively higher doses, opioid-related adverse reactions are common. Morphine is an opioid analgesic and reduces neuropathic pain, but the mechanisms underlying this reduction are unclear [93]. There are four types of known opioids receptors: delta (DORs), kappa (KORs), and mu-opioid receptors (MORs) and opioid receptor like-1 (ORL1). DOR-knockout mice showed increased neuropathic pain, implying that endogenous delta opioid activity reduces chronic pain [94]. TCAs alleviate allodynic effects in a neuropathic pain model; however, in DOR-knockout mice, the efficacy of these drugs was reduced [95]. Antidepressant drugs are still effective in MOR-knockout animals, suggesting that these drugs are regulated by DOR rather than MOR [96]. KORs are also not necessary for the effect of TCAs against neuropathic allodynia. These data indicate that DOR is the only opioid receptor that is necessary for the antiallodynic action of antidepressants [97]. In addition, ORL1 receptor agonist relieves thermal hyperalgesia after nerve injury [98].

2.3.4. Histamine Receptors. Histamine is an organic nitrogenous compound involved in local immune responses as well as in regulating physiological function. As mentioned above, Nav1.8 upregulation in primary afferents plays a critical role in the development and persistence of neuropathic pain, although the mechanisms underlying this upregulation are not fully understood. Histamine increases Nav1.8 expression in primary afferent neurons [99], while histamine receptor antagonists suppress mechanical allodynia in neuropathic rats [27].

\subsubsection{Prostaglandin E2 Receptors. Prostaglandin E2 (PGE2)} is a well-known mediator of inflammation and pain and plays a pivotal role in nociceptive processing and sensitization in the spinal cord. After nerve injury, the pain mediator, cyclooxygenase 2 (COX2), and its end product, PGE2, are persistently upregulated in invading macrophages. Nervous tissue damage induced PGE2 contributes to upregulation of BDNF in DRG neurons, leading to neuropathic pain [100].

2.3.6. CCR2. Among GPCRs, chemokines associated with the immune system are remarkable neuropathic pain modulators. Chemokines constitute a large family of relatively lowmolecular weight proteins, that is, chemoattractant cytokines controlling immune cell trafficking. MCP1 (CCL2) is a member of the CC chemokine family that specifically attracts and activates monocytes to sites of inflammation. This chemokine is absent from the normal CNS and is found after inflammation and pain, including neuropathic pain, development. CCR2, the receptor for MCP1, is expressed selectively on cells of the monocyte/macrophage lineage in the periphery and in neurons and astrocytes in the brain. Peripheral nerve injury can result in a disruption of the blood spinal cord barrier (BSCB), allowing influx of peripheral immune cells, which is mediated by MCP1. Additionally, activated microglial cells express CCR2 and modulate the CCR2-CCL2 interaction between injured primary afferent fiber terminals and dorsal horn microglia [101]. Interestingly, spinal microglia activation occurs during the early phase of neuropathic pain, suggesting that microglia may be important for initiation of neuropathic pain, while astrocytes are important for its maintenance. In addition, one study has demonstrated that CCL2/CCR2 signaling in the DRG and spinal cord is involved in neuropathic pain via distinct mechanisms [102]. Nucleus pulposus-induced mechanical allodynia is attenuated by treatment with the CCR2 antagonist RS504393 in radicular neuropathic pain. RS504393 decreased lipopolysaccharideevoked upregulation of the CCL2 and CCR2 expression and protein level in primary microglial cell cultures [103]. Mice lacking CCR2 showed substantially less hypersensitivity to mechanical stimulation after nerve injury but showed a normal response in acute pain [101]. Currently, CCR2 antagonists are in clinical trials and may be promising medicines for neuropathic pain patients in the future.

\section{Natural Products and Compounds Ameliorating Neuropathic Pain}

Natural products and compounds derived from them have shown analgesic effects in neuropathic pain models, by various modes of action (Table 1).

3.1. Food-Derived Compounds against Neuropathic Pain. A number of studies have indicated that neuroinflammation plays an important role in the induction and maintenance of chronic pain. Considering this importance, decreasing neuroinflammation through regulation of anti-inflammatory and inflammatory mediators is promising for treating neuropathic pain. According to a systematic review of natural products evaluated in neuropathic pain models, the five most researched compounds are as follows: flavonoids (28\%), terpenes (17\%), alkaloids (14\%), phenols (10\%), and carotenoids (10\%) [104]. Food-derived compounds alleviating neuropathic pain are described in Table 1 . Briefly, capsaicin is a wellknown TRPV1 agonist. Unusually, capsaicin induces pain by a single treatment but relieves pain with repeated injections [105]. Intrathecal capsaicin injection attenuates thermal hyperalgesia but does not reduce mechanical allodynia in nerve-injured rats [71].

Palmitoylethanolamide (PEA), an endogenous fatty acid amide, has been shown to perform various biological functions related to chronic and neuropathic pain and inflammation in clinical trials. PEA is an endogenous modulator found in food, such as eggs and milk, and no serious side effects to this treatment have been reported. PEA treatment was shown to relieve both thermal hyperalgesia and mechanical allodynia by regulating cannabinoid receptor 1 (CB1), peroxisome proliferator-activated receptor $\gamma(\operatorname{PPAR} \gamma)$, and TRPV1 receptors in neuropathic pain model mice [82]. In clinical studies, PEA was shown to alleviate neuropathic pain regardless of age, sex, and the pain trigger [106].

Zerumbone, a bioactive compound derived from Zingiber zerumbet was demonstrated to exert antiallodynic and antihyperalgesic effects in a CCI mouse model [89]. Additionally, most available evidence suggests that curcumin alleviates 


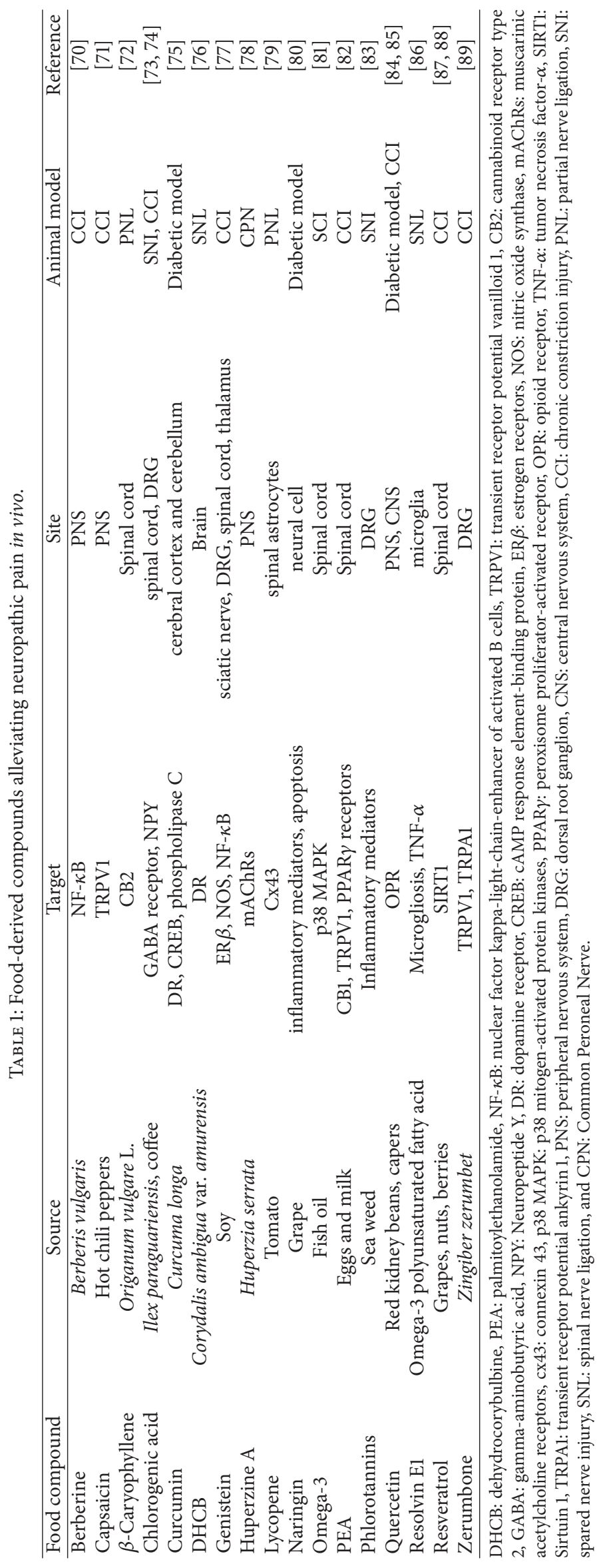


mechanical allodynia and thermal hyperalgesia in a CCI injured model $[107,108]$. This compound modulates the dopamine receptor and downregulates p300/CBP HAT activity, reducing expression of $B D N F$ and $C O X 2$ in a neuropathic pain rat model [109].

Dehydrocorybulbine (DHCB) is isolated from Corydalis yanhusuo, a traditional pain relief plant. Synthetic DHCB has efficacy in acute pain, inflammatory pain, and neuropathic pain, without side effects, such as sedation. These antinociceptive effects are reversed by a dopamine D2 agonist in the tail-flick test. DHCB exhibits affinities to dopamine receptors and displays its highest affinity to the D2 receptor [76]. Interestingly, both dopamine D2 receptor agonists and antagonists have been reported to have analgesic properties $[110,111]$.

$\beta$-Caryophyllene ( $\mathrm{BCP})$ is natural selective agonist of the peripherally expressed cannabinoid receptor 2 (CB2), an important receptor in neuropathic pain, and is found in many spices and food plants. Administration of BCP attenuated thermal hyperalgesia and mechanical allodynia and reduced spinal neuroinflammation in mouse models of inflammatory and neuropathic pain [72].

Huperzine A (HUP-A), a naturally occurring Lycopodium alkaloid, isolated from Huperzia serrata, exerts potent reversible inhibition on acetylcholinesterase and NMDA receptors, alleviating neuropathic pain, without drug tolerance and dependence [112].

Quercetin has been described as an antioxidant, antinociceptive, and anti-inflammatory compound and has preventive effects against oxaliplatin-induced painful peripheral neuropathy [113].

Berberine is a plant alkaloid that is derived from various plants and has been reported to show multiple pharmacological properties of use in several conditions, including neuropathic pain. Berberine exerts an antidepressant effect by modulating dopamine. Berberine could reduce cold and mechanical allodynia, induced by nerve injury and diabetic neuropathy $[70,114]$.

Chlorogenic acid (CGA) is a natural organic phenolic compound that is found in many plants, fruits, and vegetables, including Yerba mate. CGA has beneficial bioactivities and strong anti-inflammatory effects. In addition, administration of CGA prevented the development of mechanical hyperalgesia and attenuated histopathological changes induced by nerve injury [115].

Additionally, isoflavones are phytoestrogen used for treating hormone dysregulation like menopause and effective in diverse diseases. Genistein, a soy isoflavone, ameliorates painful neuropathy via multiple mechanisms, regulating estrogen receptor- $\beta$, and antioxidant and anti-inflammatory activities [77].

In streptozotocin-induced diabetic mice, treatment with lycopene, a carotenoid mostly found in tomatoes, attenuated neuropathic pain by inhibiting nitric oxide and TNF- $\alpha$ release [116]. In addition, treatment with lycopene notably prevented mechanical hypersensitivity and downregulated CX43 expression in the spinal dorsal horn [79].

Naringin, a flavonoid abundant in citrus fruits, such as grapefruits, has been reported to possess anti-inflammatory properties. Naringin reversed the pain response in STZinduced diabetic rats by altering expression of endogenous biomarkers [80].

Moreover, there are many studies showing that omega-3 polyunsaturated fatty acids (PUFAs) have positive effects on mood, as well as analgesic effects [117-119]. Omega-3 is effective against inflammatory pain and neuropathic pain. This compound does not interact with the pharmacodynamics or pharmacokinetics of commonly used analgesic drugs [120] and can therefore be used concomitantly with conventional analgesics. In addition, resolvin E1 derived from omega-3 also has analgesic effects in neuropathic pain [86].

Resveratrol is a natural polyphenolic compound with anti-inflammatory, cell growth-modulatory, and anticarcinogenic properties and is used to treat cardiovascular diseases, cancers, and aging. Injection of resveratrol increased the silent information regulator 1 (SIRT1) and decreased acetylhistone $\mathrm{H} 3$, alleviating neuropathic pain [87].

In addition, Harpagophytum procumbens, also known as Devil's Claw, is a plant species that has widespread medicinal uses, for treating fever, malaria, indigestion, and pain. $H$. procumbens extracts significantly reduced nerve injuryinduced mechanical allodynia [121].

Furthermore, Ginkgo biloba extract is known for its beneficial effects on brain functioning. The administration of G. biloba extract attenuates mechanical and cold allodynia in an animal model, suggesting it may be promising target for neuropathic pain. However, sedation and motor disturbance were observed with high-dose treatments [122].

3.2. CCL2/CCR2 Downregulation by Natural Compounds. CCL2 and CCR2 are involved in the pathology of a number of diseases, including rheumatoid arthritis, multiple sclerosis, atherosclerosis, asthma, and neuropathic pain [123]. Recently, pharmaceutical companies have taken an interest in the discovery and development of CCR2 antagonists for the treatment of neuropathic pain and other diseases. We and others have also attempted to find natural products with CCR2 antagonistic effects, with a view to developing new drugs or functional foods against various diseases. Many studies have indicated that natural compounds can reduce CCL2 expression in diverse models. The diallyl disulfide found in garlic inhibits TNF- $\alpha$-induced CCL2 release in vitro by suppressing CCL2-CCR2 signaling [124]. Similarly, other natural compounds, including caffeic acid, CGA, berberine, amorfrutin A, and curcumin, decrease CCL2 expression [125-129]. There are very few studies about natural compounds that alleviate neuropathic pain by inhibiting CCL2CCR2 binding, although some natural compounds have been shown to decrease the expression of CCR2 in disease models. Therefore, the compounds or plant extracts and other agents that can reduce expression of CCL2 in vitro and in vivo should be studied further to determine whether these natural compounds have potential CCR2 antagonistic effect or can reduce the CCL-CCR binding affinity in neuropathic pain models. 


\section{Conclusion}

Recently, natural products and their constitutive compounds have come to be considered as a new direction for development of analgesics and functional foods to resolve pain and pain-related problems. Most of the evidence suggests that GPCRs are the most promising potential targets for pain therapeutics, and CCR2, among the GPCRs, plays a particularly crucial role in the early phase during the onset of neuropathic pain. Overactivated microglia can also trigger neuropathic pain via CCR2-related signaling, resulting in neuroinflammation. Therefore, a CCR2 antagonist may have an effect as a neuropathic pain reliever. Further studies are needed to identify natural products that can inhibit CCL2CCR2 binding. Although toxicological and pharmacological investigations are needed to clarify the distinctive mechanism of action and evaluate their safety in humans, natural products and their compounds may be useful in the treatment of neuropathic pain.

\section{Competing Interests}

The authors declare that there is no conflict of interests regarding the publication of this paper.

\section{Acknowledgments}

This study was supported by a grant from the Korea Food Research Institute.

\section{References}

[1] T. S. Jensen, R. Baron, M. Haanpää et al., "A new definition of neuropathic pain," Pain, vol. 152, no. 10, pp. 2204-2205, 2011.

[2] N. B. Finnerup, S. Haroutounian, P. Kamerman et al., "Neuropathic pain: an updated grading system for research and clinical practice," Pain, vol. 157, no. 8, pp. 1599-1606, 2016.

[3] B. P. Yawn, P. C. Wollan, T. N. Weingarten, J. C. Watson, W. M. Hooten, and L. J. Melton III, "The prevalence of neuropathic pain: clinical evaluation compared with screening tools in a community population," Pain Medicine, vol. 10, no. 3, pp. 586$593,2009$.

[4] D. J. Gaskin and P. Richard, "The economic costs of pain in the United States," Journal of Pain, vol. 13, no. 8, pp. 715-724, 2012.

[5] P. Langley, G. Mller-Schwerfe, A. Nicolaou, H. Liedgens, J. Pergolizzi, and G. Varrassi, "The societal impact of pain in the European Union: health-related quality of life and healthcare resource utilization," Journal of Medical Economics, vol. 13, no. 3, pp. 571-581, 2010.

[6] P. C. Langley, C. Van Litsenburg, J. C. Cappelleri, and D. Carroll, "The burden associated with neuropathic pain in Western Europe," Journal of Medical Economics, vol. 16, no. 1, pp. 85-95, 2013.

[7] N. Attal, G. Cruccu, M. Haanpää et al., "EFNS guidelines on pharmacological treatment of neuropathic pain," European Journal of Neurology, vol. 13, no. 11, pp. 1153-1169, 2006.

[8] T. R. Tölle, "Challenges with current treatment of neuropathic pain," European Journal of Pain Supplements, vol. 4, supplement 2, pp. 161-165, 2010.
[9] T. S. Jensen, C. S. Madsen, and N. B. Finnerup, "Pharmacology and treatment of neuropathic pains," Current Opinion in Neurology, vol. 22, no. 5, pp. 467-474, 2009.

[10] A. L. Harvey, R. Edrada-Ebel, and R. J. Quinn, “The reemergence of natural products for drug discovery in the genomics era," Nature Reviews Drug Discovery, vol. 14, no. 2, pp. 111-129, 2015.

[11] M. Calvo, J. M. Dawes, and D. L. Bennett, "The role of the immune system in the generation of neuropathic pain," The Lancet Neurology, vol. 11, no. 7, pp. 629-642, 2012.

[12] S. P. Cohen and J. Mao, "Neuropathic pain: mechanisms and their clinical implications," British Medical Journal, vol. 348, article f7656, 2014.

[13] F. A. White, H. Jung, and R. J. Miller, "Chemokines and the pathophysiology of neuropathic pain," Proceedings of the National Academy of Sciences of the United States of America, vol. 104, no. 51, pp. 20151-20158, 2007.

[14] L. Ranieri, E. Antoncecchi Jr., S. D’Alonzo et al., "Evaluation of left ventricular function by polycardiographic analysis in hemodialyzed children," Giornale Italiano di Cardiologia, vol. 13, no. 2, pp. 82-85, 1983.

[15] W. Wang, J. Gu, Y.-Q. Li, and Y.-X. Tao, "Are voltage-gated sodium channels on the dorsal root ganglion involved in the development of neuropathic pain?" Molecular Pain, vol. 7, article 16, 2011.

[16] C. J. Woolf and M. W. Salter, "Neuronal plasticity: increasing the gain in pain," Science, vol. 288, no. 5472, pp. 1765-1768, 2000.

[17] K. Inoue and M. Tsuda, "Microglia and neuropathic pain," Glia, vol. 57, no. 14, pp. 1469-1479, 2009.

[18] L. R. Watkins and S. F. Maier, "Beyond neurons: evidence that immune and glial cells contribute to pathological pain states," Physiological Reviews, vol. 82, no. 4, pp. 981-1011, 2002.

[19] J.-T. Liou, F.-C. Liu, C.-C. Mao, Y.-S. Lai, and Y.-J. Day, "Inflammation confers dual effects on nociceptive processing in chronic neuropathic pain model," Anesthesiology, vol. 114, no. 3, pp. 660-672, 2011.

[20] R.-R. Ji, Z.-Z. Xu, and Y.-J. Gao, "Emerging targets in neuroinflammation-driven chronic pain," Nature Reviews Drug Discovery, vol. 13, no. 7, pp. 533-548, 2014.

[21] A. Ellis and D. L. H. Bennett, "Neuroinflammation and the generation of neuropathic pain," British Journal of Anaesthesia, vol. 111, no. 1, pp. 26-37, 2013.

[22] F. Marchand, M. Perretti, and S. B. McMahon, "Role of the immune system in chronic pain," Nature Reviews Neuroscience, vol. 6, no. 7, pp. 521-532, 2005.

[23] C. I. Svensson, M. Schäfers, T. L. Jones, H. Powell, and L. S, Sorkin, "Spinal blockade of TNF blocks spinal nerve ligationinduced increases in spinal P-p38," Neuroscience Letters, vol. 379, no. 3, pp. 209-213, 2005.

[24] S. Taves, T. Berta, G. Chen, and R.-R. Ji, "Microglia and spinal cord synaptic plasticity in persistent pain," Neural Plasticity, vol. 2013, Article ID 753656, 10 pages, 2013.

[25] R. McKelvey, T. Berta, E. Old, R.-R. Ji, and M. Fitzgerald, "Neuropathic pain is constitutively suppressed in early life by anti-inflammatory neuroimmune regulation," The Journal of Neuroscience, vol. 35, no. 2, pp. 457-466, 2015.

[26] K. Ren and R. Dubner, "Interactions between the immune and nervous systems in pain," Nature Medicine, vol. 16, no. 11, pp. 1267-1276, 2010.

[27] Y. Zuo, N. M. Perkins, D. J. Tracey, and C. L. Geczy, "Inflammation and hyperalgesia induced by nerve injury in the rat: a key role of mast cells," Pain, vol. 105, no. 3, pp. 467-479, 2003. 
[28] A. Paladini, M. Fusco, S. Coaccioli, S. D. Skaper, and G. Varrassi, "Chronic pain in the elderly: the case for new therapeutic strategies," Pain Physician, vol. 18, no. 5, pp. E863-E876, 2015.

[29] N. Borregaard, O. E. Sørensen, and K. Theilgaard-Mönch, "Neutrophil granules: a library of innate immunity proteins," Trends in Immunology, vol. 28, no. 8, pp. 340-345, 2007.

[30] N. M. Perkins and D. J. Tracey, "Hyperalgesia due to nerve injury: role of neutrophils," Neuroscience, vol. 101, no. 3, pp. 745757, 2000.

[31] C. M. Peters, J. M. Jimenez-Andrade, B. M. Jonas et al., "Intravenous paclitaxel administration in the rat induces a peripheral sensory neuropathy characterized by macrophage infiltration and injury to sensory neurons and their supporting cells," Experimental Neurology, vol. 203, no. 1, pp. 42-54, 2007.

[32] T. Liu, N. van Rooijen, and D. J. Tracey, "Depletion of macrophages reduces axonal degeneration and hyperalgesia following nerve injury," Pain, vol. 86, no. 1-2, pp. 25-32, 2000.

[33] W. M. Campana, "Schwann cells: activated peripheral glia and their role in neuropathic pain," Brain, Behavior, and Immunity, vol. 21, no. 5, pp. 522-527, 2007.

[34] X. Li, S. L. Gonias, and W. M. Campana, "Schwann cells express erythropoietin receptor and represent a major target for Epo in peripheral nerve injury," Glia, vol. 51, no. 4, pp. 254-265, 2005.

[35] S. C. Keswani, U. Buldanlioglu, A. Fischer et al., "A novel endogenous erythropoietin mediated pathway prevents axonal degeneration," Annals of Neurology, vol. 56, no. 6, pp. 815-826, 2004.

[36] G. Moalem, K. Xu, and L. Yu, "T lymphocytes play a role in neuropathic pain following peripheral nerve injury in rats," Neuroscience, vol. 129, no. 3, pp. 767-777, 2004.

[37] D. J. Tracey and J. S. Walker, "Pain due to nerve damage: are inflammatory mediators involved," Inflammation Research, vol. 44, no. 10, pp. 407-411, 1995.

[38] H. Machelska, P. J. Cabot, S. A. Mousa, Q. Zhang, and C. Stein, "Pain control in inflammation governed by selectins," Nature Medicine, vol. 4, no. 12, pp. 1425-1428, 1998.

[39] W. Gui, X. Wei, C. Mai et al., "Interleukin-1 overproduction is a common cause for neuropathic pain, memory deficit, and depression following peripheral nerve injury in rodents," Molecular Pain, vol. 12, 2016.

[40] Y. Kawasaki, Z.-Z. Xu, X. Wang et al., "Distinct roles of matrix metalloproteases in the early- and late-phase development of neuropathic pain," Nature Medicine, vol. 14, no. 3, pp. 331-336, 2008.

[41] T. Feng, Q. Yin, Z.-L. Weng et al., "Rapamycin ameliorates neuropathic pain by activating autophagy and inhibiting interleukin-1 $\beta$ in the rat spinal cord," Journal of Huazhong University of Science and Technology-Medical Science, vol. 34, no. 6, pp. 830-837, 2014.

[42] Y. Kawasaki, L. Zhang, J.-K. Cheng, and R.-R. Ji, "Cytokine mechanisms of central sensitization: distinct and overlapping role of interleukin- $\beta$, interleukin- 6 , and tumor necrosis factor$\alpha$ in regulating synaptic and neuronal activity in the superficial spinal cord," Journal of Neuroscience, vol. 28, no. 20, pp. 51895194, 2008.

[43] A. George, C. Schmidt, A. Weishaupt, K. V. Toyka, and C. Sommer, "Serial determination of tumor necrosis factor-alpha content in rat sciatic nerve after chronic constriction injury," Experimental Neurology, vol. 160, no. 1, pp. 124-132, 1999.

[44] P. Andrade, G. Hoogland, J. S. Del Rosario, H. W. Steinbusch, V. Visser-Vandewalle, and M. A. Daemen, "Tumor necrosis factor$\alpha$ inhibitors alleviation of experimentally induced neuropathic pain is associated with modulation of TNF receptor expression," Journal of Neuroscience Research, vol. 92, no. 11, pp. 1490-1498, 2014.

[45] J. Xu, X. E, H. Liu et al., "Tumor necrosis factor-alpha is a potential diagnostic biomarker for chronic neuropathic pain after spinal cord injury," Neuroscience Letters, vol. 595, pp. 3034, 2015.

[46] J.-G. Cui, S. Holmin, T. Mathiesen, B. A. Meyerson, and B. Linderoth, "Possible role of inflammatory mediators in tactile hypersensitivity in rat models of mononeuropathy," Pain, vol. 88, no. 3, pp. 239-248, 2000.

[47] M. S. Ramer, M. D. Kawaja, J. T. Henderson, J. C. Roder, and M. A. Bisby, "Glial overexpression of NGF enhances neuropathic pain and adrenergic sprouting into DRG following chronic sciatic constriction in mice," Neuroscience Letters, vol. 251, no. 1, pp. 53-56, 1998.

[48] T. Tanaka, M. Minami, T. Nakagawa, and M. Satoh, "Enhanced production of monocyte chemoattractant protein-1 in the dorsal root ganglia in a rat model of neuropathic pain: possible involvement in the development of neuropathic pain," Neuroscience Research, vol. 48, no. 4, pp. 463-469, 2004.

[49] M. A. Nassar, A. Levato, L. C. Stirling, and J. N. Wood, "Neuropathic pain develops normally in mice lacking both $\mathrm{Na}_{v} 1.7$ and $\mathrm{Na}_{v} 1.8$," Molecular Pain, vol. 1, article 24, 2005.

[50] M. S. Minett, S. Falk, S. Santana-Varela et al., "Pain without nociceptors? Nav1.7-independent pain mechanisms," Cell Reports, vol. 6, no. 2, pp. 301-312, 2014.

[51] X.-W. Dong, S. Goregoaker, H. Engler et al., "Small interfering RNA-mediated selective knockdown of NaV1.8 tetrodotoxinresistant sodium channel reverses mechanical allodynia in neuropathic rats," Neuroscience, vol. 146, no. 2, pp. 812-821, 2007.

[52] J. Yan, K. Zou, X. Liu et al., "Hyperexcitability and sensitization of sodium channels of dorsal root ganglion neurons in a rat model of lumber disc herniation," European Spine Journal, vol. 25, no. 1, pp. 177-185, 2016.

[53] B. C. Hains, J. P. Klein, C. Y. Saab, M. J. Craner, J. A. Black, and S. G. Waxman, "Upregulation of sodium channel Navl.3 and functional involvement in neuronal hyperexcitability associated with central neuropathic pain after spinal cord injury," The Journal of Neuroscience, vol. 23, no. 26, pp. 8881-8892, 2003.

[54] O. A. Samad, A. M. Tan, X. Cheng, E. Foster, S. D. Dib-Hajj, and S. G. Waxman, "Virus-mediated shRNA knockdown of $\mathrm{Na}_{\mathrm{v}} 1.3$ in rat dorsal root ganglion attenuates nerve injury-induced neuropathic pain," Molecular Therapy, vol. 21, no. 1, pp. 49-56, 2013.

[55] C. Aurilio, V. Pota, M. C. Pace, M. B. Passavanti, and M. Barbarisi, "Ionic channels and neuropathic pain: phisiopatology and applications," Journal of Cellular Physiology, vol. 215, no. 1, pp. 8-14, 2008.

[56] M. M. Jagodic, S. Pathirathna, P. M. Joksovic et al., "Upregulation of the T-type calcium current in small rat sensory neurons after chronic constrictive injury of the sciatic nerve," Journal of Neurophysiology, vol. 99, no. 6, pp. 3151-3156, 2008.

[57] A. Dogrul, L. R. Gardell, M. H. Ossipov, F. C. Tulunay, J. Lai, and F. Porreca, "Reversal of experimental neuropathic pain by T-type calcium channel blockers," Pain, vol. 105, no. 1-2, pp. 159168, 2003.

[58] H. Saegusa, T. Kurihara, S. Zong et al., "Suppression of inflammatory and neuropathic pain symptoms in mice lacking the $\mathrm{N}$ type $\mathrm{Ca}^{2+}$ channel," EMBO Journal, vol. 20, no. 10, pp. 23492356, 2001. 
[59] J. D. Richardson, S. Kilo, and K. M. Hargreaves, "Cannabinoids reduce hyperalgesia and inflammation via interaction with peripheral CB1 receptors," Pain, vol. 75, no. 1, pp. 111-119, 1998.

[60] K. R. Bley, "Recent developments in transient receptor potential vanilloid receptor 1 agonist-based therapies," Expert Opinion on Investigational Drugs, vol. 13, no. 11, pp. 1445-1456, 2004.

[61] D. Vilceanu, P. Honore, Q. H. Hogan, and C. L. Stucky, "Spinal nerve ligation in mouse upregulates TRPV1 heat function in injured IB4-positive nociceptors," Journal of Pain, vol. 11, no. 6, pp. 588-599, 2010.

[62] Y.-J. Qu, X. Zhang, Z.-Z. Fan et al., "Effect of TRPV4-p38 MAPK pathway on neuropathic pain in rats with chronic compression of the dorsal root ganglion," BioMed Research International, vol. 2016, Article ID 6978923, 12 pages, 2016.

[63] J. W. Olney and N. B. Farber, "NMDA antagonists as neurotherapeutic drugs, psychotogens, neurotoxins, and research tools for studying schizophrenia," Neuropsychopharmacology, vol. 13, no. 4, pp. 335-345, 1995.

[64] T. Klabunde and G. Hessler, "Drug design strategies for targeting G-protein-coupled receptors," ChemBioChem, vol. 3, no. 10, pp. 928-944, 2002.

[65] G. H. Lee and S. S. Kim, "Therapeutic strategies for neuropathic pain: potential application of pharmacosynthetics and optogenetics," Mediators of Inflammation, vol. 2016, Article ID 5808215, 11 pages, 2016.

[66] Y. S. Gwak and C. E. Hulsebosch, "GABA and central neuropathic pain following spinal cord injury," Neuropharmacology, vol. 60, no. 5, pp. 799-808, 2011.

[67] G. M. Drew, P. J. Siddall, and A. W. Duggan, "Mechanical allodynia following contusion injury of the rat spinal cord is associated with loss of GABAergic inhibition in the dorsal horn," Pain, vol. 109, no. 3, pp. 379-388, 2004.

[68] Y. S. Gwak, E. D. Crown, G. C. Unabia, and C. E. Hulsebosch, "Propentofylline attenuates allodynia, glial activation and modulates GABAergic tone after spinal cord injury in the rat," Pain, vol. 138, no. 2, pp. 410-422, 2008.

[69] J. G. Meisner, A. D. Marsh, and D. R. Marsh, "Loss of GABAergic interneurons in laminae I-III of the spinal cord dorsal horn contributes to reduced GABAergic tone and neuropathic pain after spinal cord injury," Journal of Neurotrauma, vol. 27, no. 4, pp. 729-737, 2010.

[70] H. J. Kim, "Berberine ameliorates allodynia induced by chronic constriction injury of the sciatic nerve in rats," Journal of Medicinal Food, vol. 18, no. 8, pp. 909-915, 2015.

[71] K. Zhang, S. Ramamurthy, T. J. Prihoda, and M. S. Eckmann, "Effect of delayed intrathecal administration of capsaicin on neuropathic pain induced by chronic constriction injury of the sciatic nerve in rats," Journal of Pain Research, vol. 7, pp. 547554, 2014.

[72] A.-L. Klauke, I. Racz, B. Pradier et al., "The cannabinoid $\mathrm{CB}_{2}$ receptor-selective phytocannabinoid beta-caryophyllene exerts analgesic effects in mouse models of inflammatory and neuropathic pain," European Neuropsychopharmacology, vol. 24, no. 4, pp. 608-620, 2014.

[73] D. W. Lim, J. G. Kim, T. Han et al., "Analgesic effect of Ilex paraguariensis extract on postoperative and neuropathic pain in rats," Biological and Pharmaceutical Bulletin, vol. 38, no. 10, pp. 1573-1579, 2015.

[74] K. Hara, Y. Haranishi, K. Kataoka et al., "Chlorogenic acid administered intrathecally alleviates mechanical and cold hyperalgesia in a rat neuropathic pain model," European Journal of Pharmacology, vol. 723, no. 1, pp. 459-464, 2014.
[75] T. P. Kumar, S. Antony, G. Gireesh, N. George, and C. S. Paulose, "Curcumin modulates dopaminergic receptor, CREB and phospholipase $\mathrm{C}$ gene expression in the cerebral cortex and cerebellum of streptozotocin induced diabetic rats," Journal of Biomedical Science, vol. 17, article 43, 2010.

[76] Y. Zhang, C. Wang, L. Wang et al., "A novel analgesic isolated from a traditional Chinese medicine," Current Biology, vol. 24, no. 2, pp. 117-123, 2014.

[77] A. E. Valsecchi, S. Franchi, A. E. Panerai, P. Sacerdote, A. E. Trovato, and M. Colleoni, "Genistein, a natural phytoestrogen from soy, relieves neuropathic pain following chronic constriction sciatic nerve injury in mice: anti-inflammatory and antioxidant activity," Journal of Neurochemistry, vol. 107, no. 1, pp. 230-240, 2008.

[78] Z.-X. Zuo, Y.-J. Wang, L. Liu et al., "Huperzine A alleviates mechanical allodynia but not spontaneous pain via muscarinic acetylcholine receptors in mice," Neural Plasticity, vol. 2015, Article ID 453170, 11 pages, 2015.

[79] F. F. Zhang, N. Morioka, T. Kitamura et al., "Lycopene ameliorates neuropathic pain by upregulating spinal astrocytic connexin 43 expression," Life Sciences, vol. 155, pp. 116-122, 2016.

[80] A. D. Kandhare, K. S. Raygude, P. Ghosh, A. E. Ghule, and S. L. Bodhankar, "Neuroprotective effect of naringin by modulation of endogenous biomarkers in streptozotocin induced painful diabetic neuropathy," Fitoterapia, vol. 83, no. 4, pp. 650-659, 2012.

[81] J. D. Figueroa, K. Cordero, M. Serrano-Illan et al., "Metabolomics uncovers dietary omega-3 fatty acid-derived metabolites implicated in anti-nociceptive responses after experimental spinal cord injury," Neuroscience, vol. 255, pp. $1-18,2013$.

[82] B. Costa, F. Comelli, I. Bettoni, M. Colleoni, and G. Giagnoni, "The endogenous fatty acid amide, palmitoylethanolamide, has anti-allodynic and anti-hyperalgesic effects in a murine model of neuropathic pain: involvement of CB1, TRPV1 and PPAR $\gamma$ receptors and neurotrophic factors," Pain, vol.139, no. 3, pp. 541$550,2008$.

[83] J. G. Kim, D. W. Lim, S. Cho, D. Han, and Y. T. Kim, “The edible brown seaweed Ecklonia cava reduces hypersensitivity in postoperative and neuropathic pain models in rats," Molecules, vol. 19, no. 6, pp. 7669-7678, 2014.

[84] M. Anjaneyulu and K. Chopra, "Quercetin, a bioflavonoid, attenuates thermal hyperalgesia in a mouse model of diabetic neuropathic pain," Progress in Neuro-Psychopharmacology and Biological Psychiatry, vol. 27, no. 6, pp. 1001-1005, 2003.

[85] S. Çivi, G. Emmez, Ü. A. Dere, A. Ö. Börcek, and H. Emmez, "Effects of quercetin on chronic constriction nerve injury in an experimental rat model," Acta Neurochirurgica, vol. 158, no. 5, pp. 959-965, 2016.

[86] Z.-Z. Xu, T. Berta, and R.-R. Ji, "Resolvin E1 inhibits neuropathic pain and spinal cord microglial activation following peripheral nerve injury," Journal of Neuroimmune Pharmacology, vol. 8, no. 1, pp. 37-41, 2013.

[87] Q. Yin, F.-F. Lu, Y. Zhao et al., "Resveratrol facilitates pain attenuation in a rat model of neuropathic pain through the activation of spinal Sirtl," Regional Anesthesia \& Pain Medicine, vol. 38, no. 2, pp. 93-99, 2013.

[88] A. Kumar and S. S. Sharma, "NF- $\kappa$ B inhibitory action of resveratrol: a probable mechanism of neuroprotection in experimental diabetic neuropathy," Biochemical and Biophysical Research Communications, vol. 394, no. 2, pp. 360-365, 2010. 
[89] N. A. Zulazmi, B. Gopalsamy, A. A. Omar Farouk, M. R. Sulaiman, B. H. Bharatham, and E. K. Perimal, "Antiallodynic and antihyperalgesic effects of zerumbone on a mouse model of chronic constriction injury-induced neuropathic pain," Fitoterapia, vol. 105, pp. 215-221, 2015.

[90] J. Ferreira, A. Beirith, M. A. S. Mori et al., "Reduced nerve injury-induced neuropathic pain in kinin B1 receptor knockout mice," Journal of Neuroscience, vol. 25, no. 9, pp. 2405-2412, 2005.

[91] J. Lai, M.-C. Luo, Q. Chen et al., "Dynorphin A activates bradykinin receptors to maintain neuropathic pain," Nature Neuroscience, vol. 9, no. 12, pp. 1534-1540, 2006.

[92] R. H. Dworkin, A. B. O'Connor, J. Audette et al., "Recommendations for the pharmacological management of neuropathic pain: an overview and literature update," Mayo Clinic Proceedings, vol. 85, no. 3, supplement, pp. S3-S14, 2010.

[93] S. J. Hirsch and A. H. Dickenson, "Morphine sensitivity of spinal neurons in the chronic constriction injury neuropathic rat pain model," Neuroscience Letters, vol. 562, pp. 97-101, 2014.

[94] X. Nadal, J.-E. Baños, B. L. Kieffer, and R. Maldonado, "Neuropathic pain is enhanced in $\delta$-opioid receptor knockout mice," European Journal of Neuroscience, vol. 23, no. 3, pp. 830-834, 2006.

[95] M. Benbouzid, C. Gavériaux-Ruff, I. Yalcin et al., "Delta-opioid receptors are critical for tricyclic antidepressant treatment of neuropathic allodynia," Biological Psychiatry, vol. 63, no. 6, pp. 633-636, 2008.

[96] Y. Bohren, D. Karavelic, L.-H. Tessier et al., "Mu-opioid receptors are not necessary for nortriptyline treatment of neuropathic allodynia," European Journal of Pain, vol. 14, no. 7, pp. 700-704, 2010.

[97] S. Megat, Y. Bohren, S. Doridot et al., " $\kappa$-opioid receptors are not necessary for the antidepressant treatment of neuropathic pain," British Journal of Pharmacology, vol. 172, no. 4, pp. 1034-1044, 2015.

[98] T. Yamamoto, N. Nozaki-Taguchi, and S. Kimura, "Effects of intrathecally administered nociceptin, an opioid receptor-likel (ORL1) receptor agonist, on the thermal hyperalgesia induced by unilateral constriction injury to the sciatic nerve in the rat," Neuroscience Letters, vol. 224, no. 2, pp. 107-110, 1997.

[99] J.-X. Yue, R.-R. Wang, J. Yu et al., "Histamine upregulates Nav1.8 expression in primary afferent neurons via $\mathrm{H} 2$ receptors: involvement in neuropathic pain," CNS Neuroscience and Therapeutics, vol. 20, no. 10, pp. 883-892, 2014.

[100] P. Cruz Duarte, B. St-Jacques, and W. Ma, "Prostaglandin E2 contributes to the synthesis of brain-derived neurotrophic factor in primary sensory neuron in ganglion explant cultures and in a neuropathic pain model," Experimental Neurology, vol. 234, no. 2, pp. 466-481, 2012.

[101] C. Abbadie, J. A. Lindia, A. M. Cumiskey et al., "Impaired neuropathic pain responses in mice lacking the chemokine receptor CCR2," Proceedings of the National Academy of Sciences of the United States of America, vol. 100, no. 13, pp. 7947-7952, 2003.

[102] X. Zhu, S. Cao, M.-D. Zhu, J.-Q. Liu, J.-J. Chen, and Y.-J. Gao, "Contribution of chemokine CCL2/CCR2 signaling in the dorsal root ganglion and spinal cord to the maintenance of neuropathic pain in a rat model of lumbar disc herniation," Journal of Pain, vol. 15, no. 5, pp. 516-526, 2014.

[103] A. Piotrowska, K. Kwiatkowski, E. Rojewska et al., "Direct and indirect pharmacological modulation of CCL2/CCR2 pathway results in attenuation of neuropathic pain - in vivo and in vitro evidence," Journal of Neuroimmunology, vol. 297, pp. 9-19, 2016.

[104] J. S. S. Quintans, Â. R. Antoniolli, J. R. G. S. Almeida, V. J. Santana-Filho, and L. J. Quintans-Júnior, "Natural products evaluated in neuropathic pain models-a systematic review," Basic and Clinical Pharmacology and Toxicology, vol. 114, no. 6, pp. 442-450, 2014.

[105] H. Knotkova, M. Pappagallo, and A. Szallasi, "Capsaicin (TRPV1 agonist) therapy for pain relief: farewell or revival?" Clinical Journal of Pain, vol. 24, no. 2, pp. 142-154, 2008.

[106] A. Paladini, M. Fusco, T. Cenacchi, C. Schievano, A. Piroli, and G. Varrassi, "Palmitoylethanolamide, a special food for medical purposes, in the treatment of chronic pain: a pooled data metaanalysis," Pain Physician, vol. 19, no. 2, pp. 11-24, 2016.

[107] X. Zhao, Y. Xu, Q. Zhao, C.-R. Chen, A.-M. Liu, and Z.-L. Huang, "Curcumin exerts antinociceptive effects in a mouse model of neuropathic pain: descending monoamine system and opioid receptors are differentially involved," Neuropharmacology, vol. 62, no. 2, pp. 843-854, 2012.

[108] F.-T. Ji, J.-J. Liang, L. Liu, M.-H. Cao, and F. Li, "Curcumin exerts antinociceptive effects by inhibiting the activation of astrocytes in spinal dorsal horn and the intracellular extracellular signalregulated kinase signaling pathway in rat model of chronic constriction injury," Chinese Medical Journal, vol. 126, no. 6, pp. 1125-1131, 2013.

[109] X. Zhu, Q. Li, R. Chang et al., "Curcumin alleviates neuropathic pain by inhibiting $\mathrm{p} 300 / \mathrm{CBP}$ histone acetyltransferase activityregulated expression of BDNF and Cox-2 in a rat model," PLoS ONE, vol. 9, no. 3, Article ID e91303, 2014.

[110] N. Cobacho, J. L. de la Calle, and C. L. Paíno, "Dopaminergic modulation of neuropathic pain: analgesia in rats by a D2-type receptor agonist," Brain Research Bulletin, vol. 106, pp. 62-71, 2014.

[111] R. N. Freedenfeld, M. Murray, P. N. Fuchs, and R. S. Kiser, "Decreased pain and improved quality of life in fibromyalgia patients treated with olanzapine, an atypical neuroleptic," Pain Practice, vol. 6, no. 2, pp. 112-118, 2006.

[112] D. Yu, D. K. Thakor, I. Han et al., "Alleviation of chronic pain following rat spinal cord compression injury with multimodal actions of huperzine A," Proceedings of the National Academy of Sciences of the United States of America, vol. 110, no. 8, pp. E746E755, 2013.

[113] M. I. Azevedo, A. F. Pereira, R. B. Nogueira et al., "The antioxidant effects of the flavonoids rutin and quercetin inhibit oxaliplatin-induced chronic painful peripheral neuropathy," Molecular Pain, vol. 9, article 53, 2013.

[114] S. O. Kim and H. J. Kim, "Berberine ameliorates cold and mechanical allodynia in a rat model of diabetic neuropathy," Journal of Medicinal Food, vol. 16, no. 6, pp. 511-517, 2013.

[115] D. Bagdas, N. Cinkilic, H. Y. Ozboluk, M. O. Ozyigit, and M. S. Gurun, "Antihyperalgesic activity of chlorogenic acid in experimental neuropathic pain," Journal of Natural Medicines, vol. 67, no. 4, pp. 698-704, 2013.

[116] A. Kuhad, S. Sharma, and K. Chopra, "Lycopene attenuates thermal hyperalgesia in a diabetic mouse model of neuropathic pain," European Journal of Pain, vol. 12, no. 5, pp. 624-632, 2008.

[117] P. M. Kidd, "Omega-3 DHA and EPA for cognition, behavior, and mood: clinical findings and structural-functional synergies with cell membrane phospholipids," Alternative Medicine Review, vol. 12, no. 3, pp. 207-227, 2007. 
[118] J. E. Manson, "Pain: sex differences and implications for treatment," Metabolism: Clinical and Experimental, vol. 59, supplement 1, pp. S16-S20, 2010.

[119] R. J. Goldberg and J. Katz, "A meta-analysis of the analgesic effects of omega-3 polyunsaturated fatty acid supplementation for inflammatory joint pain," Pain, vol. 129, no. 1-2, pp. 210-223, 2007.

[120] H. Shapiro, "Could n-3 polyunsaturated fatty acids reduce pathological pain by direct actions on the nervous system?" Prostaglandins Leukotrienes and Essential Fatty Acids, vol. 68, no. 3, pp. 219-224, 2003.

[121] D. W. Lim, J. G. Kim, D. Han, and Y. T. Kim, "Analgesic effect of harpagophytum procumbens on postoperative and neuropathic pain in rats," Molecules, vol. 19, no. 1, pp. 1060-1068, 2014.

[122] Y. S. Kim, H. J. Park, T. K. Kim, D. E. Moon, and H. J. Lee, "The effects of ginkgo biloba extract EGB 761 on mechanical and cold allodynia in a rat model of neuropathic pain," Anesthesia and Analgesia, vol. 108, no. 6, pp. 1958-1963, 2009.

[123] N. L. Subasinghe, J. Lanter, T. Markotan et al., "A novel series of $\mathrm{N}$-(azetidin-3-yl)-2-(heteroarylamino)acetamide CCR2 antagonists," Bioorganic and Medicinal Chemistry Letters, vol. 23, no. 4, pp. 1063-1069, 2013.

[124] D. Bauer, E. Mazzio, K. F. Soliman et al., "Diallyl disulfide inhibits TNF $\alpha$-induced CCL2 release by MDA-MB-231 cells," Anticancer Research, vol. 34, no. 6, pp. 2763-2770, 2014.

[125] H.-P. Zhao, J. Feng, K. Sun et al., "Caffeic acid inhibits acute hyperhomocysteinemia-induced leukocyte rolling and adhesion in mouse cerebral venules," Microcirculation, vol. 19, no. 3, pp. 233-244, 2012.

[126] H. Shi, L. Dong, X. Dang et al., "Effect of chlorogenic acid on LPS-induced proinflammatory signaling in hepatic stellate cells," Inflammation Research, vol. 62, no. 6, pp. 581-587, 2013.

[127] F. Zimetti, M. P. Adorni, N. Ronda, R. Gatti, F. Bernini, and E. Favari, "The natural compound berberine positively affects macrophage functions involved in atherogenesis," Nutrition, Metabolism and Cardiovascular Diseases, vol. 25, no. 2, pp. 195201, 2015.

[128] H. Shi, J. Ma, C. Mi et al., "Amorfrutin A inhibits TNF- $\alpha$ induced NF- $\kappa \mathrm{B}$ activation and NF- $\kappa \mathrm{B}$-regulated target gene products," International Immunopharmacology, vol. 21, no. 1, pp. 56-62, 2014.

[129] Z.-J. Zhang, L.-X. Zhao, D.-L. Cao, X. Zhang, Y.-J. Gao, and C. Xia, "Curcumin inhibits LPS-induced CCL2 expression via JNK Pathway in C6 rat astrocytoma cells," Cellular and Molecular Neurobiology, vol. 32, no. 6, pp. 1003-1010, 2012. 

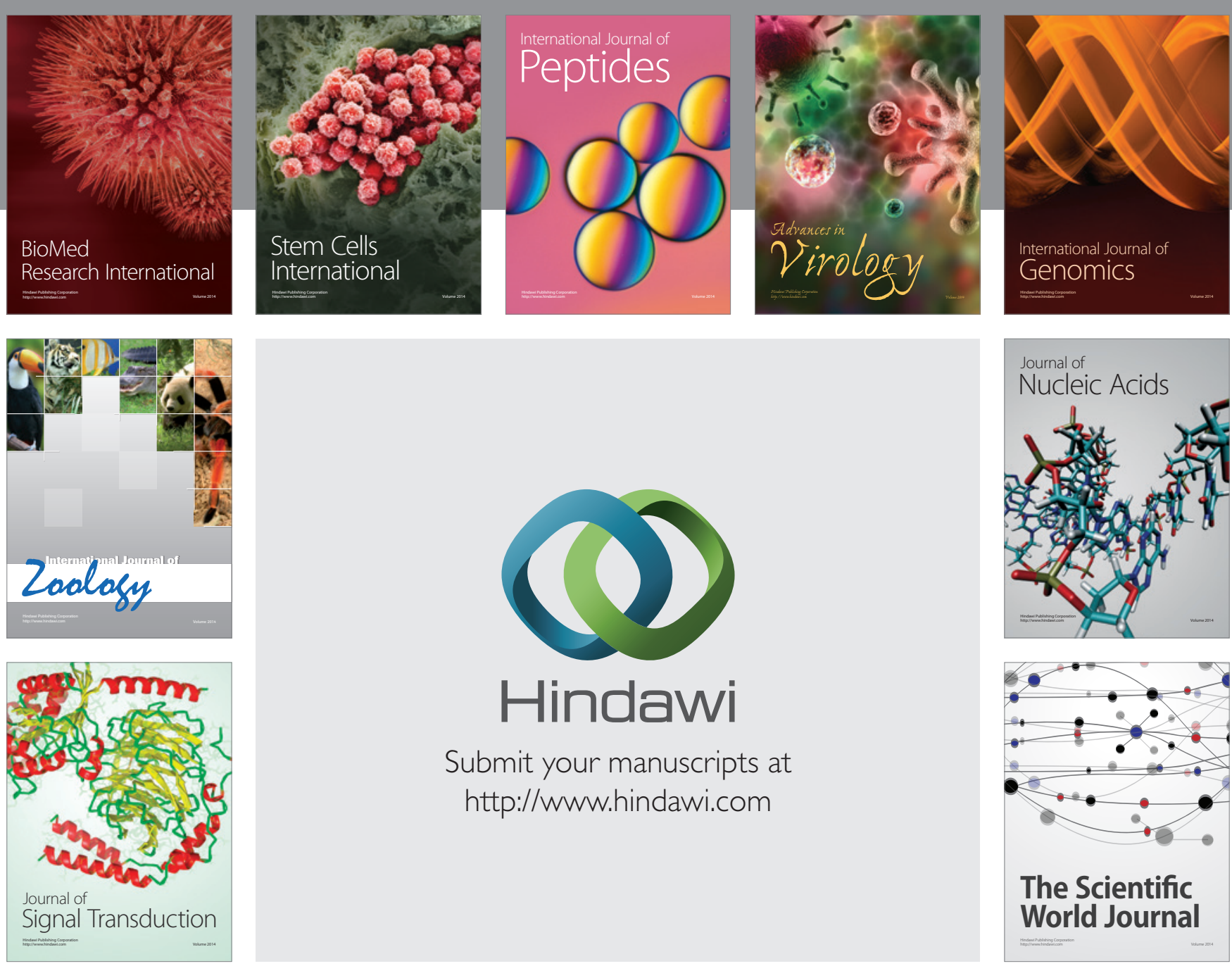

Submit your manuscripts at

http://www.hindawi.com
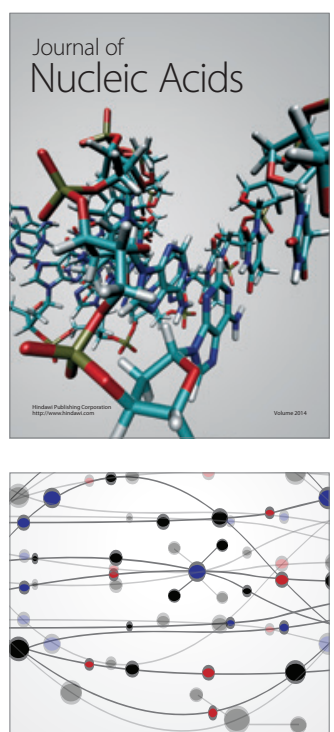

The Scientific World Journal
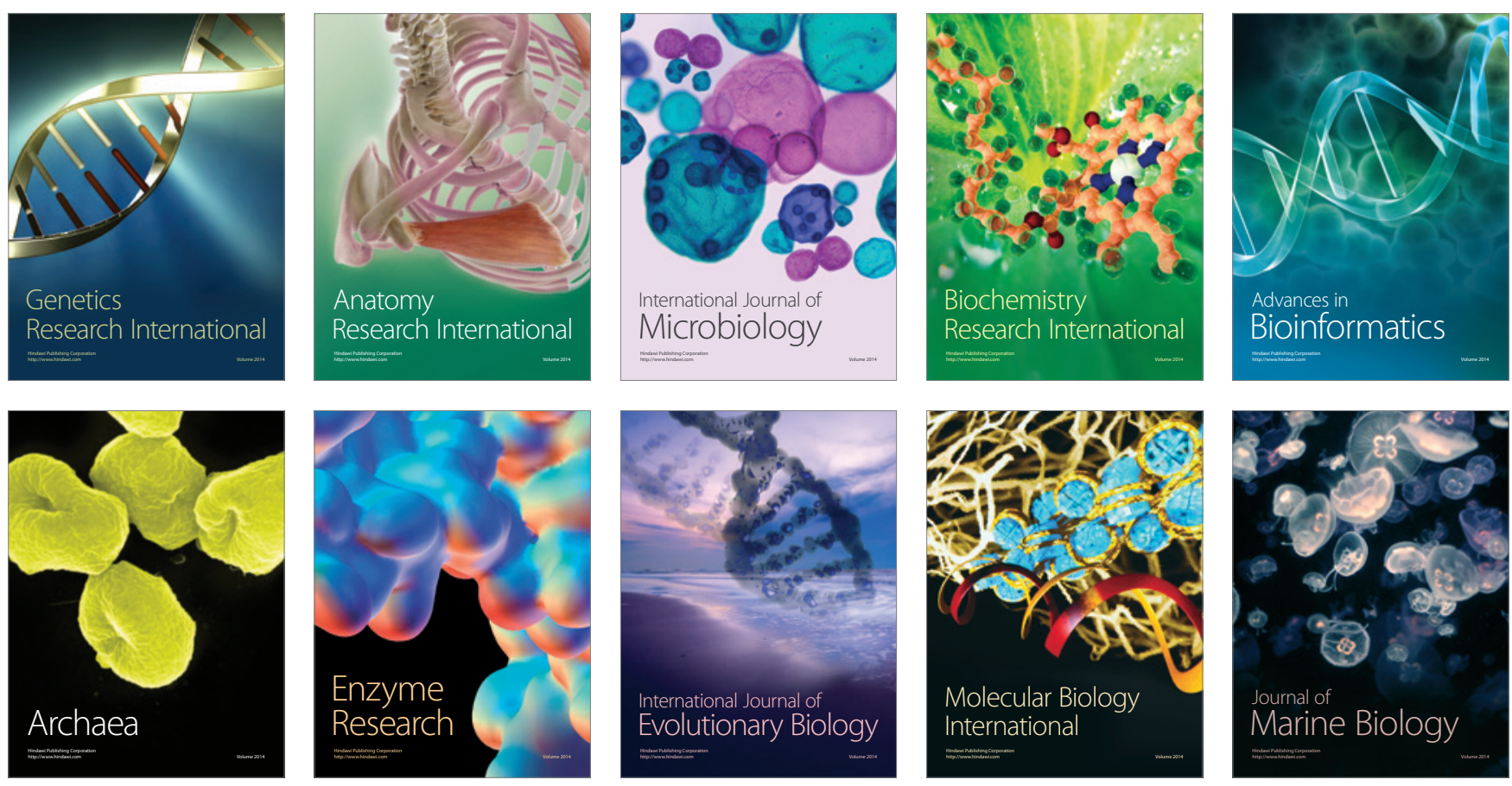